\title{
SHEA Co-sponsors Consensus Conference on the Clinical Investigation of Nosocomial Pneumonia
}

The First International Consensus

Conference on the Clinical

Investigation of Ventilator-

Associated Pneumonia was

convened in Memphis, Tennessee,

on M ay 14-15, 1992. The

conference was co-sponsored by the College of Medicine, University of

Tennessee, Memphis, the American College of Chest Physicians, and

SHEA. Dr.C. G Ien Mayhall filed this report; more details can be found in the June quarterly

Newsletter.

The Consensus Conference was chaired by Dr. Waldemar (Buzz) G. Johanson, Jr. Fii-three clinical investigators participated in the conference and were assigned to one of five groups: Group I, Bronchoscopic Technique; Group II, Patient Selection for Clinical Investigation; Group III, Standardization for Viewing and Evaluating the Chest Radiograph; Group IV, Laboratory Diagnosis of Pneumonia; and Group V, Methodology for Clinical Investigation. SHEA participants included Drs. Walter J. Hierholzer, Jr., Richard A. Garibaldi, Donald E. Craven, Peter A. Gross, and C. Glen Mayhall. All participants from SHEA were assigned to Group V.

The conference was guided by a preconference consensus document. During the first day of the conference, each group met to achieve consensus on the points that had remained controversial. On the second day of the conference, each group presented the changes in its section, and the consensus document was "fine tuned" and finalized. It will be published simultaneously in Chest and in Infection Control and Hospital Epidemiology this fall.

The Conference attempted to establish uniform scientific standards for the definition, diagnosis, and the clinical and epidemiologic investigation of nosocomial pneumonia. The Conference further sought to establish new standards for culturing respiratory secretions and new scientific guidelines for the investigation of antimicrobial therapy for nosocomial pneumonia. The ultimate goal of the conference was to improve the quality of the scientific investigation of ventilator-associated pneumonia and to provide a standardized approach to investigation that will facilitate meaningful comparisons of data from different centers.

C. Glen Mayhall, MD

Memphis, Tennessee

\section{Position Papers on Deck}

The Surgical Wound Surveillance Position Papers, which were initiated by SHEA as a joint effort with the Surgical Infection Society, the Association of Practitioners for Infection Control (APIC), and the Centers for Disease Control are due to be published in Infection Control and Hospital Epidemiology this October as well as in APIC's journal and in a surgical journal. In addition to a consensus document, there will be a publication that standardizes definitions for superficial and deep infections.

These definitions with the case-mix adjuster and surveillance standards should be of use not only to practitioners and researchers but also to regulatory agencies.

The Lookback Position Paper produced by the SHEA AIDS Committee has been approved by the SHEA Board and should be available soon for publication.

\section{SHEA N ews and N ewsletter Editor Search}

The five-year term of the current editor of the Journal's SHEA News and of the SHEA quarterly Newsletter expires in December 1992. The Publications Committee is anxious to receive names of individuals who wish to be considered as candidates for this position. SHEA members who are interested and those who would like to submit names of candidates should contact Dr. William Scheckler, Chair, Publications Committee, Department of Family Medicine and Practice, University of Wisconsin, 777 South Mills St., Madison, WI 53715. Telephone (608) 263-3637; FAX (608) 263-5813.

Brief items of interest for the SHEA News or Newsletter may be sent to Robert A. Weinstein, MD, SHEA, N ewsletter Editor, Division of Infectious Diseases, Michael Reese Hospital, Lake Shore Drive at 31st St., Chicago, IL 60616; FAX (312) 7913577. Copy must be typed, doublespaced, and may not exceed five pages. 